\title{
Model variables of risk elements in sexual behaviour: a comparative analysis of Lagos-based traders
}

\author{
Olatunji Babatola \\ Department of Geography, University of Lagos, Akoka, Yaba, Lagos, Nigeria \\ drbabatola@yahoo.com, obabtola@unilag.edu.ng \\ Telephone: +23418778617
}

\section{Abstract}

This paper compares sexuality risk variables and the logit models of itinerantly differentiated tradesmen groups in Lagos Nigeria.

The study, using survey design, compared the groups' biosocial characteristics and then their sexuality risk variables in two ways. First, it compared their relative vulnerabilities to sexually transmitted infections, using selected 'life-time' and recent sexuality parameters. Second, it examined the degree of similarity between the groups' sexuality risk models. Findings show significant bio-social contrasts between the two groups. While circulators showed greater multi-partnership risk, the non-circulators exceeded marginally on commercial sexuality. Condom-use risk was undifferentiating. Also, the variables in their respective parsimonious risk models showed minimal contrast. The findings among others underscore the relevance of HIVIAIDS sufferers as campaign persons and canvassed for greater emphasis on family life programmes, given the riskier sexuality disposition of married tradesmen, regardless of circulation status.

Key words: Sexual, risk-behaviour, circulators, non-circulators, modelling

\section{Résumé}

Cet article compare les variables de risques de la sexualité avec les modèles de la régression logistique de groupes des commerçants se distinguant par itinéraire à Lagos, Nigéria. Utilisant un plan de sondage, cette étude a comparé leurs traits biosociaux avec leurs variables de risques de la sexualité de deux façons. Premièrement, l'étude a comparé leurs vulnérabilités relatives aux infections transmises sexuellement, utilisant des paramètres de la vie et de la sexualité récemment sélectionnés. Deuxièmement, elle a examiné le degré de similarité entre les modèles des risques de la sexualité des groupes. Cette recherche démontre les contrastes biosociaux importants entre les deux groupes. Si les circulateurs ont montré un grand risque en multipartenariat, les non-circulateurs étaient marginalement excessifs en sexualité commerciale. Le risque d'usage des préservatifs était peu pertinent. Aussi, les variables retenues dans leurs respectifs modèles parsimonieux de risques de la sexualité ont démontré un contraste minimal. Cette recherche souligne la nécessité d'usage des victimes du VHI/SIDA pour la campagne contre la maladie et la pertinence des programmes à l'intention des familles, vu l'inclination des commerçants mariés au sexe risqué, malgré leurs 
statuts de circulation.

Mots clés: Sexuelle, comportement à risque, circulateurs, noncirculateurs, modélisation

\section{Introduction}

The appearance of HIV/AIDS has aroused much interest in sexual behavioural analysis. A preference for surveybased studies is noticeable. They examine in general, sexual behavioural risk of study populations, aiming at isolating socio-economic and or sexuality variables that could provide the clue for appropriate HIV/AIDS policy and programmes. Major findings have emphasized that sexual practices of adolescents/youths, commercial sex workers, and itinerant/migratory workers/employees constitute greater heterosexual sources of HIV/AIDS infiltration and exacerbation in many populations.

Of the three identified groups, the mobile population group has attracted the least and scanty research attention in Nigeria, despite certain compelling facts to do otherwise. First, although the current national prevalence level of HIV/AIDS is below $5 \%$, its arithmetic rates of decline belittle the worth of the campaign and programmatic efforts designed to curtail its spread. The obvious inequality between efforts and achievement on HIV/AIDS prevalence, suggests the existence of other avenues of HIV/AIDS epidemics, which are currently poorly appreciated and poorly incorporated in the various efforts. Second, the simultaneous occurrence of the rapid increases in the rate of seroprevalence - for example, from $1.8 \%$ in 1990 to $5.8 \%$ in 200 I (NACA 2005) - and the surge in international popula- tion mobility since the early 80 s, due to economic downturn, may not be fortuitous. Besides, a number of Nigerian cities that function actively as nodal points of local and international population mobility are known to have had, or currently have HIV/AIDS infection rates, which exceed(ed) the national average. Lagos, to a large extent, falls into this category. It is Nigeria's largest metropolis and her foremost local and international melting pot. Although official statistics indicate a sub-national seroprevalence level for Lagos, the popular opinion is that much of the current statistics on Lagos, including those on HIV/ AIDS, is at best a poor approximation (NACA 2005). Indeed, the age-old tradition of passive interest in data acquisition and management generally by public institutions, and the preponderance of those who patronize informal health outlets corroborate the notion that both the levels and dimensions of HIV/AIDS for Lagos are poorly discerned.

The above scenario calls for more clarifying studies on Lagos; especially studies which compare the sexual risk characteristics of traders who engage in international commercial travels and those who do not.

It is in this context that this paper examines and compares the risk elements in the sexual behaviour of itinerant and non-itinerant traders in Lagos, and their respective explanatory factors. 


\section{Literature review and conceptual framework}

Analysis of sexuality risk in the context of itinerant livelihoods as noted above, constitutes a meagre proportion of sexual behavioural studies on Nigeria. A number of studies, which examined sexual vulnerability in the context of migration or itinerancy, adopted a rather narrow perspective. For example, studies by Orubuloye, Caldwell and Caldwell (1994); Anarfi, Appiah and Awusabo-Asare (1997) which claimed that riskier tendencies typify the sexual behaviour of itinerant individuals failed to weigh the relative importance of relevant variables. To date, the long-haul drivers (Orubuloye, Caldwell and Caldwell. (1993), Marck. (1999)), the commercial intra-city drivers (Ekanem, Afolabi, Nuga and Adebayo (2005)); as well as the intra-national women traders (Omorodion (1993)) are the major groups on which varying degrees of analysis have been carried out. Besides the scant number of studies on mobile population groups studied so far, most of the existing sexuality risk studies adopted inadequate analytical and or methodological scopes in the treatment of vital aspects of sexuality risks, in contrast to studies (for example, Lurie, William, Zuma et al. (2003) and Mudandi, Vissers, Voeten et al. (2006), which employed non-migratory control groups. In other words, majority of studies, which aimed at showing the greater inclination of itinerant groups for risky sexuality, generally omit any comparable control population. The major challenge in this regard, however, goes beyond having just any control group, but having a control group that is contextually appropriate.
Furthermore, many of the existing comparative sexual risk studies explore inadequate number of sexual risk variables. The fact however, is that no two of the three major sexual risk variables, namely, multi-partner sex, commercial sex and no-condom sex, have identical capabilities in transmitting known sexual infections. Varga's (1997) finding that discordant sexual partners often retain their negative serum status, despite repeated unprotected sex with their respective infected partners, implies that a reliable inter-group analysis of sexual risk requires more than examining just one or two sexuality risk variables, as is often the practice.

The preceding observations informed the conceptual framework employed in this paper. It adapts Prothero's (1977) analysis, which examines the connection between human spatial mobility and liability to diseases, in the light of more recent studies (Anarfi 1992, 1993; Lurie, Williams, Zuma, Mkaya-Nwamburi, Garnett, Sturm et al. (2003); Marck (1999) etc), which also explore the link between itinerancy and vulnerability to sexual infections.

Mobility or itinerancy in essence is conceptualised as a dichotomous variable. The 'ever-moved' refers to traders who have engaged or still engage in international business travels, while the 'never-moved' traders (or non-circulators) have never been involved in commerce-related international travels. Itinerancy, however, for both groups excludes the idea of local travels for commerce or non-commercial purposes. Two major sets of factors, that capture the bio-social and precedent sexuality variables, which in previous 
studies (Anarfi and Antwi(1995), Adegbola and Babatola(1999), Babatola (2006) and Osagbemi, Joseph, Adepetu, Nyong and Jegede (2007)) were identified as influencing in varying degrees and context, the tendency for risky sex, have been selected for analysis. The selected bio-social factors include age, marital status, and formal education, size of mobilised business capital resources, childhood environment and religious orientation. Religion is expressed in terms denomination membership, as the study population is predominantly Christian. The second set of independent variables comprises precedent sexuality variables, namely, age at first sexual experience, duration since first-time awareness of HIV/AIDS, previous STD experience, voluntary submission to HIV/AIDS test as well as the subjective notion on HIV/AIDS. Conceptually, age at first sex and the duration since the first-time awareness of HIV/AIDS may or may not associate with a greater orientation for vulnerable sex, in contrast to previous experience of STI, which is expected to associate with a lesser risk of vulnerable sex.

Previous voluntary submission to HIV/AIDS test in most cases could be an expression of the fear of the possibility of being infected by the one who submits. The fear may arise from the consciousness of one's vulnerable previous sexual practices, or that of one's regular sexual partner. The notion or perception of self-immunity to HIV/ AIDS infection is included in the analysis in view of its being highlighted in sexual networking literature. It was said to associate with a tendency for fatalism on issues of health and death, or with the idea that Africans possess stronger genetic resistance to infections in general (Orubuloye and Oguntimehin 1999).

The study assumes also that migrants' selectivity factor - which in theory expects migrants or itinerant group to contrast bio-socially with nonitinerant group - may also differentiate mobile and non-mobile groups with respect to the nature or the degrees of their sexuality risk practices. This informs the decision to employ a more inclusive set of explanatory variables in the analysis.

Comparison of sexual risk was carried out at two levels. The first compared respectively, selected 'life-time' and 'recent' sexuality risk variables. At the second level, the analysis examined whether or not the sets of variables, which associate in varying degrees with the committal of a specified sexuality risk variable respectively for the two groups are comparable

Briefly, the focus of this paper is addressed by the following related questions. (I) Given the theoretical implications of migrants' selectivity, to what extent are the bio-socio attributes of circulators and non-circulators comparable. (2) What are the basic risk elements that characterize the sexual behaviour of the two groups and to what extent do they contrast; and (3) to what extent are the respective models of risky sexuality for both groups comparable?

\section{Data and method}

This study used a survey method, utilizing the market-based strategy for easy access to the study population. It employed two sets of questionnaires 
designed to study a larger problem of population circulation and the risk to sexual health in Lagos Nigeria. The first activity was a reconnaissance to solicit the support of traders through their guild/association leaders, and to assist in critical decisions about the sampling exercise.

The study markets and selection criteria

Four major markets were selected for the sampling of respondents, based on some set out objective criteria. The markets are, the Auto Spare Parts Dealers Association Market (ASPADAM), which deals primarily in auto spares; the Alaba International market, where electrical and electronics are the main merchandise and the Balogun International Centre for Commerce, where imported processed foods, household durable goods, cosmetics, pharmaceutical, beautician gadgets and textiles predominate. These three markets are located along Lagos-Benin Republic International highway. The fourth market, which is the White Sand Market, trades in food merchandise purchased in countries within the West African region. It is located at Oyingbo, adjacent to Lagos' traditional Central Business District.

Three major criteria guided the choice of the study markets. (I) A market is selected if its trading population comprises both international circulatory and non-circulatory traders. This is to minimize the possible number of elements, which may further differentiate risky sexual practices of the two groups, apart from the differences associated with their involvement or noninvolvement in international commercial travels. (2) Irregular markets, which have no permanent arrangement of stalls or traders, were left out. (3) Any market which functions as an appendage of another bigger one within the metropolis was dropped, to avoid double listing of traders that have multiple shops in those trading outlets.

Identification of the population

$$
\text { groups }
$$

To be considered as part of the total population, a trader must reside primarily in Lagos, and own a stall in one of the selected commercial centres. A circulatory trader must in addition have at least a previous record of international commercial travel. Information obtained during reconnaissance pegs the circulators' overseas trip duration to between few days and a maximum of 8 weeks. Hence, the fieldwork was planned to last for three months December 2004 to March 2005 - to ensure that a circulator who was sampled but had travelled, returns before the end of the fieldwork for questionnaire administration.

\section{The sampling procedure and administration of instrument}

The fieldwork proper commenced with the numbering of relevant stall(s)/ store(s), relying essentially on the locality arrangement of goods. The two population groups were treated as independent samples. To ensure anonymity, the number assigned to a stall in a trading locality identified the owner in that locality. The assigned serial number to each stall/trader was written out also in paper slips, to produce two independent sampling frames; from which random sampling without replacement was carried out separately for each group. Trained fieldworkers administered the two sets of questionnaires 
that contained both open-ended and structured questions. Traders who declined were substituted by randomly reselecting from the remaining pool of the paper slips.

Sample size appropriation

Although the total population of noncirculators exceeded that of the circulators, the same sample sizes were selected for both groups for two reasons.

First, the two groups were treated as independent samples. Second, the circulators' questionnaires had nearly twice the number of questions in the non-circulators' questionnaire; as it focuses on more issues, than the present paper considers. And given that the larger the number of the independent variables in a logistic regression analysis, the larger the recommended sample size (Hopskin 200I), the compromise decision was to select equal samples for both groups. The study targeted a minimum of 800 and a maximum of 1000 respondents. At the end of fieldwork, 450 questionnaires per group were coded and analysed. Table I shows the selected markets' population and their estimated samples.

Table I The selected markets/estimated samples

\begin{tabular}{lcccc}
\hline \multicolumn{1}{c}{ Name of market } & \multicolumn{2}{c}{ Total population size } & \multicolumn{2}{c}{ Estimated population size } \\
& Non-circ & Circulators & Non-circ & Circulators \\
\hline ASPMDA & 2,756 & 208 & 71 & 24 \\
ALABA (International) & 3,300 & 500 & 85 & 58 \\
BALOGUN (ICC) & 11,400 & 3,172 & 293 & 367 \\
OYINGBO & 800 & 250 & 20 & 29 \\
Total & 17,456 & 3,880 & 450 & 450 \\
$\quad$ Cumulative total & & 21,336 & & 900 \\
\hline
\end{tabular}

Research variables and analysis

Both questionnaires tapped information on respondents' socio-economic, demographic and relevant cultural variables, in addition to those on sexual practices and attitudes. The first analysis compares the socio-economic characteristics of the two groups, with a statistical test of selected variables. In the second analysis selected sexuality risk variables, namely, Age at first sexual experience (AGESEX), Total sexual partners ever-had (TSEPH), Exposure duration to active sexuality (EDAS), and Mean sexual partners per duration of sexuality exposure (MSPED), for the two populations were compared. Analy- sis of more recent sexuality variables compared the number of sexual partners, up to a maximum of three partners in the last one year, the use/non-use of condom with each of the indicated sexual partners, as well as the number of the specified partners that are commercial sex partners, testing for significance in the observed differences. Commercial sex work is operationalized according to Orubuloye and Caldwell (1994)'s definition, which defines it as giving or receiving monetary gifts for sex, especially when such sexual engagements are non-marital and casual in nature. Thereafter, the $\mathrm{BSTEP}_{(\mathrm{L})}$ procedure of the logistic regression 
analysis was employed to compare the set of variables retained in the parsimonious models of sexuality risk. Series of variables were entered based on theoretical expectation as well as cue from literature. The major variables selected were age, marital status, youth period environment, education, business capital, business experience, age at first sex experience, previous experience of sexual infection, and relative recency of HIV knowledge. The analysis relied both on the $\mathrm{R}^{2}$ and the Hosmer-Lemeshow significance values for model assessment. SPSS version 12 was used for statistical data analysis.

\section{Results}

Table 2 compares the socio-economic and other relevant characteristics of the two groups. Several interesting facts emerge from the table. The sex pattern shows male domination as 86.6 and 95.I percents respectively of circulators and non- circulators are men. It is a major trait of the selected markets, which differ from the normal markets found in different parts of the metropolis. The age patterns of the two groups appear similar. The non-circulators' mean age of 31.9 years is however remarkably lower than the 36.6 mean age of itinerant traders. Hence only 16.2 percent of circulators are within the 18-24 age brackets in contrast to 44.5 per cent of non-circulators. Over 90 per cent of both trader groups are of Igbo ethnic extraction, which reflects in the religion pattern, as most lgbo are Christians. The Catholics (50.2\%) dominate the non-circulator in contrast to the relative dominance of Orthodox/

The size of business capital employed further attests to this claim.
Protestants (35.8\%) among the circulators. A greater percent of circulators $(59.1 \%)$ than non-circulators $(37 \%)$ is married. The modal education group in both cases is Primary Six/Full Secondary, which accounts for 48 and 67.8 per cents respectively of circulators and non-circulators. A greater concentration of circulators $(22.4 \%)$ to non-circulators (1I.6\%) occurs in the Post Secondary group. The better exposure of circulators and their stronger financial means suggest that more of their members take advantage of upward educational mobility through numerous distance-learning opportunities in Lagos.The implication is that the observed educational classification pattern of the circulators most likely reflects a pattern that is transforming rather than a static one.

Duration of stay in Lagos shows that more of the circulators (12.4\%) than non-circulators (7.8\%) were Lagos-born.

The modal percentage (39.8) of circulators had lived in Lagos for between 16 40 years in contrast to non-circulators' 0 - 9 years modal class (40.4\%). Business experience corresponds with age variable. Slightly above 48 per cent of circulators have been in business for at least 12 years in contrast to $21.2 \%$ of non-circulators in that category. The modal class for non-circulators (43.7\%) is $1-7$ years of business experience in contrast to 12-32 business experience years $(48.1 \%)$ among circulators. The pattern shows that the circulators are generally more firmly established in business than their non-circulatory counterparts.

Greater proportions of circulators employ larger business capital. The 
African Population Studies Vol $\square 5$, I (April $\square 0 I I)$

Table 2 Selected socio-demographic characteristics of non-circulators and circulators

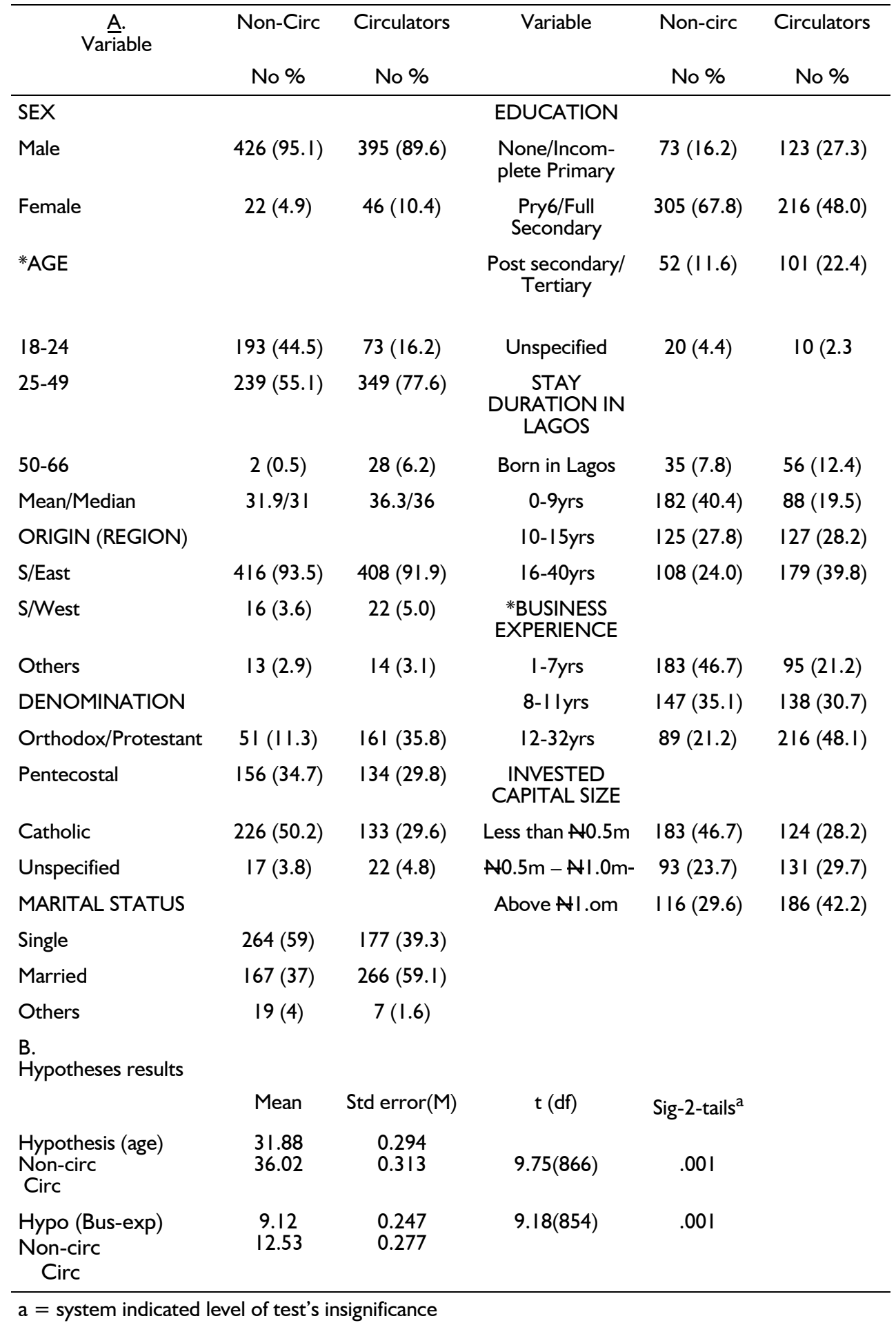


Table 3 General sexuality parameters

\begin{tabular}{|c|c|c|c|c|c|c|}
\hline & \multicolumn{3}{|c|}{ Non-circulators } & \multicolumn{3}{|c|}{ Circulators } \\
\hline & Mean & Median & $\mathrm{N}$ & Mean & Median & $\mathrm{N}$ \\
\hline Age at first sexual intercourse & 19.5 & 19.0 & 324 & 20.8 & 21 & 342 \\
\hline Total sexual partners had ${ }^{\mathrm{a}}$ & 8.2 & 6.0 & 408 & 14.8 & 6.5 & 412 \\
\hline Exposure duration of active sex & 12.5 & 12.0 & 327 & 15.4 & 15 & 324 \\
\hline Mean total sexual partners ${ }^{b}$ & 0.76 & 0.52 & 292 & 1.2 & 0.54 & 308 \\
\hline
\end{tabular}

a: This captures the mean of sexual partners ever had

b: Expresses ' $a$ ' as a numerator of the number of years since first sexual experience

NImillion (US\$8000) and above capital base is the modal class (42.2\%) among circulators in contrast to 46.7 per cents of non-circulators which employed less than $\mathrm{N} 0.5 \mathrm{~m}$ (US\$4000). Analyses of the two groups so far show that they differ on many biosocial attributes, which may affect their risky sexual practices. The results of the 'mean age' and the 'years of business experience' tested for significance are illustrated in section ' $B$ ' of Table 2. The age variable shows that on the average the circulators $(M=36.06$, $\mathrm{SE}=0.313)$ are significantly older than non-circulators $(M=31.88, S E=0.294)$ with $p=.00 \mathrm{I}$. The hypothesis of the equality of business experience in years also shows that on the average, the circulators years of business experience $(M=12 . .53, S E=0.277)$ is significantly higher than that of non-circulators $(M=9.12, S E=0.247)$, also at $p=.00 \mathrm{I}$ level .

\section{Risk dimensions in sexual transactions}

Table 3 compares the patterns of four selected past sexuality variables for the two groups. First, the mean and the median ages of non-circulators at first sex experience are comparatively lower. Second, the relatively younger mean age of the non-circulators at sex- ual debut, did not translate to a larger number of total sexual partners everhad (TSPEH) by them. Third, the mean of thetotal sexual partners ever had by the circulators (14.8) is by far greater than that of the non-circulators (8.2). Fourth, the difference in the median values of the two groups' total sexual partners since first sexual experience is small, in contrast to a larger difference between their mean scores. The observed contrast suggests that only a small proportion of the circulators have extremely large sex partner values, which exaggerated the difference between their mean scores.

The mean of exposure duration to active sexuality is 15.4 years for circulators in contrast to 12.5 years for noncirculators. This also tends to suggest that a few circulators are indeed characterized by super-medial sexual partnership trait.

\section{Recent sexual risk variables}

Table 4 compares the values of the three more recent sexual variables for the two groups. It shows the proportions of each group that had between I and 3 sexual partners in the last year, and the percentage values of commercial sexual partnership and condom use default. Exactly 352 (74.2\%) circulators 
had at least one sexual partner in the year preceding the study, compared to the 320 (7I.1\%) of non-circulators. Slightly more than 85 per cent of the 352 circulators that had a first partner also had a second partner, while 81.5 per cent of them (287) proceeded to the level of a third sexual partner. By contrast, lower percentages of non-circulators who had a first sexual partner had a second $(66.5 \%)$ and a third sexual partner $(60.2 \%)$ respectively.

The pattern of the commercial sex partnership variable differs from that of multi-partnership sex. Greater percentages of non-circulators engaged paid sexual partners at each level. About 7l percent of non-circulators engaged commercial sex partners at the first intercourse level. It reduced marginally to 70.6 and 68.6 per cent respectively at the second and third levels. The magnitudes of pay-for-sex among the circulators were generally lower: $41.7 \%$, $46.5 \%$ and $48.1 \%$ respectively at the three levels of sexual partnership. The assessment of comparative risk based on the use or non-use of condom is rather blurred between the groups. For example, more of non-circulators (20.5\%) than circulators (13.9\%) defaulted with first partner, in contrast to greater levels of default by circulators with second and third sexual partners. That is, 23.6 and 31.4 per cents of circulators defaulted with the second and third partners, in contrast to 22.9 and 25.8 per cent respectively by noncirculators.

The results in section $B$ of the table show the t-test statistical outcomes of the three null hypotheses, which posited that the mean values of both groups on each of the three sexuality variables are not different. The outcome of the first hypothesis shows that on the average, the size of circulators sexual partners $(M=2.62, S E=.045)$ is significantly higher than that of the non-circulators' $(M=2.25, S E=.053)$ at $p=.00 \mathrm{I}$. The result of the second hypothesis shows that on the average, the greater patronage tendency for commercial sexual partners by non-circulators (M = I.I4, SE =. 060) narrowly missed being significantly higher than that of the circulators $(M=.95, S E$ $=.062$ ); given the $p=.026$. On the other hand, results of the third hypothesis clearly shows that the apparently higher level of non-condom sex by circulators ( $M=1.25, \mathrm{SE}=.074)$ is highly insignificantly different from that of the non-circulators $(M=1.03, S E=.093)$., given the $p$-value of .066 .

\section{Comparative logistic re- gression modelling of commercial sexuality risk}

The ten initial hypothesized variables of sexuality risks were reduced to seven after a detailed cross-tabulation analysis between each independent variable and the selected sexuality risk variables. Furthermore, attempts to fit a model respectively for multi-partner and condom default risk did not converge; it did however, for commercial sexuality risk. The Backward Step (likelihood) analysis compared the models of commercial sexuality, i.e. whether respondents engaged a commercial sexual partner in the last one-year. The seven categorical variables include: youth period environment, marital status, age, education, business experience in years, age at first sex, and experience of sexual infection. 
Table 4 Multi-Partnership sex, commercial sex and condom-use risks among circulators and non-circulators

\begin{tabular}{|c|c|c|c|c|c|}
\hline \multirow{2}{*}{$\begin{array}{l}\text { A. Sexuality } \\
\text { Risk Variables }\end{array}$} & \multirow{2}{*}{$\begin{array}{l}\text { Committal } \\
\text { Level }\end{array}$} & \multicolumn{2}{|c|}{ Non-Circulator } & \multicolumn{2}{|c|}{ Circulator } \\
\hline & & $\mathrm{N}$ & $\%$ & $\mathrm{~N}$ & $\%$ \\
\hline \multirow{3}{*}{ Multi-Partnership Risk ${ }^{\mathrm{a}}$} & I Partner Level & 322 & $(71.6)$ & 352 & $(78.2)$ \\
\hline & $\begin{array}{l}2 \text { Partners } \\
\text { Level }\end{array}$ & 214 & $(66.5)$ & 301 & $(85.5)$ \\
\hline & 3 Partners level & 194 & $(60.2)$ & 287 & $(8 \mid .5)$ \\
\hline \multirow{3}{*}{ Commercial Sex Risk ${ }^{b}$} & I Partner Level & 230 & (7I.4) & 147 & $(4 \mid .7)$ \\
\hline & $\begin{array}{l}2 \text { Partners } \\
\text { Level }\end{array}$ & $15 \mid$ & $(70.6)$ & 140 & $(46.5)$ \\
\hline & $\begin{array}{l}3 \text { Partners } \\
\text { Level }\end{array}$ & 133 & $(68.6)$ & 138 & $(48.1)$ \\
\hline \multirow{3}{*}{$\begin{array}{l}\text { Inappropriate/Default in condom } \\
\text { use }{ }^{\text {b }}\end{array}$} & I Partner Level & 66 & $(20.5)$ & 49 & $(13.9)$ \\
\hline & $\begin{array}{l}2 \text { Partners } \\
\text { Level }\end{array}$ & 49 & $(22.9)$ & 71 & $(23.6)$ \\
\hline & $\begin{array}{l}3 \text { Partners } \\
\text { Level }\end{array}$ & 50 & $(25.8)$ & 90 & $(31.4)$ \\
\hline \multicolumn{6}{|l|}{ B. Hypotheses results } \\
\hline & Mean (M) & $\begin{array}{c}\text { Std } \\
\text { error }(M)\end{array}$ & $t(d f)$ & $\begin{array}{l}\text { Sig-2- } \\
\text { tails }^{c}\end{array}$ & \\
\hline $\begin{array}{c}\text { Multi-partner sex Non-circ } \\
\text { Circ }\end{array}$ & $\begin{array}{l}2.25 \\
2.62\end{array}$ & $\begin{array}{l}.053 \\
0.045\end{array}$ & $5.34(672)$ & .001 & \\
\hline $\begin{array}{c}\text { Commercial sex Non-circ } \\
\text { Circ }\end{array}$ & $\begin{array}{l}1.14 \\
0.95\end{array}$ & $\begin{array}{l}0.06 \\
0.062\end{array}$ & $-2.23(892)$ & .026 & \\
\hline $\begin{array}{c}\text { Condon-default Non-circ } \\
\text { Circ }\end{array}$ & $\begin{array}{l}1.03 \\
1.25\end{array}$ & $\begin{array}{l}.093 \\
.074\end{array}$ & $1.85(326)$ & .066 & \\
\hline
\end{tabular}

Source: Fieldwork Survey (Dec - March) 2004/2005

$\mathrm{a}=$ The percentage values at the $2^{\text {nd }}$ and $3^{\text {rd }}$ levels of multi-partner sex were obtained by expressing the respective $\mathrm{N}$-values as a numerator of the number that engaged a first sexual partner.

$\mathrm{b}=$ The percentage values for both commercial sexuality and condom risks were obtained by expressing the $N$ value at a given partnership level, as numerator of the corresponding $\mathrm{N}$ - value of the multi-partner sexuality risk. $\mathrm{C}=$ system indicated level of test's significance 
African Population Studies Vol $\square 5$, I (April $\square 0 I I)$

Table 5 Results of the first step iteration non-circulators \& circulators

\begin{tabular}{|c|c|c|c|c|c|c|c|c|}
\hline \multirow{2}{*}{$\begin{array}{l}\text { Model Categorical } \\
\text { Variables }\end{array}$} & \multicolumn{4}{|c|}{ Non-Circulators } & \multicolumn{4}{|c|}{ Circulators } \\
\hline & B & SE & Wald & Odds & B & SE & Wald & Odds \\
\hline $\begin{array}{c}\text { Youth environment } \\
\text { Village(ref) }\end{array}$ & & & 2.695 & & & & 4.527 & \\
\hline Large towns(I) & -.312 & .874 & .127 & .732 & 1.257 & .898 & 1.960 & 3.515 \\
\hline Lagos(2) & .568 & .943 & .363 & 1.764 & 1.733 & .909 & $3.632 *$ & 5.655 \\
\hline $\begin{array}{l}\text { aMarital status } \\
\text { Marital status }(I)\end{array}$ & -5.001 & .748 & 44.676 **** & .007 & $3 . \overline{5} 79$ & .450 & $\begin{array}{l}63.203 * * \\
*\end{array}$ & .028 \\
\hline $\begin{array}{c}\text { Age } \\
\text { Youngest (ref) }\end{array}$ & & & 3.596 & & & & 4.206 & \\
\hline Median age(I) & -1.593 & .841 & 3.589* & .203 & .958 & .586 & 2.669 & 2.606 \\
\hline Oldest(2) & -.993 & .719 & 1.905 & .371 & .082 & .502 & .027 & 1.086 \\
\hline $\begin{array}{c}\text { Education } \\
\text { None/Incomplete PRY } \\
\text { (ref) }\end{array}$ & & & 3.274 & & & & 1.779 & \\
\hline Full Pry/Secondary(I) & 1.455 & .869 & $2.804 *$ & 4.283 & -.677 & .508 & $\mathrm{I} .774$ & .508 \\
\hline Post Secondary(2) & 1.173 & .696 & $2.843^{*}$ & 3.231 & -.377 & .419 & .810 & .686 \\
\hline $\begin{array}{c}\text { Business experience in } \\
\text { years } \\
\text { Minimum Experience } \\
\text { (ref) }\end{array}$ & & & $6.282 * *$ & & & & .737 & \\
\hline Median Experience (I) & 1.440 & .640 & $5.055^{* *}$ & 4.220 & -.456 & .535 & .727 & .787 \\
\hline $\begin{array}{l}\text { Maximum experience in } \\
\text { years }(2)\end{array}$ & 1.342 & .594 & $5.107^{* *}$ & 3.825 & -.239 & .498 & .230 & .787 \\
\hline $\begin{array}{l}\text { Age at first sex } \\
\text { Early entrants (refo }\end{array}$ & & & $5.709 *$ & & & & 3.793 & \\
\hline Later entrant $(I)$ & -.002 & .527 & .000 & .998 & .718 & .431 & $2.773 *$ & 2.050 \\
\hline Latest entrant (2) & 1.215 & .583 & $5.099 * *$ & 3.369 & .693 & .400 & 2.999* & 2.000 \\
\hline $\begin{array}{l}{ }^{\text {aPrevious experience of }} \\
\text { sexual infection }(I)\end{array}$ & 2.223 & .547 & 16.517 & 9.237 & 1.043 & .383 & 7.435***** & 2.838 \\
\hline Constant & .130 & 1.072 & .015 & 1.139 & -.422 & 1.002 & .177 & .656 \\
\hline Nagelkerkes' $\mathrm{R}^{2}$ & & & $59.3 \%$ & & & & $7.4 \%$ & \\
\hline $\begin{array}{c}\text { Hosmer-Lemeshow 's } \\
\chi \text {, df } \rho,\end{array}$ & & 5.4 & $3 ; 8 ; .709$ & & & 5.71 & $3 ; 8 ; .679$ & \\
\hline $\begin{array}{l}\text {-2Loglikelihood } \\
\text { improvement }\end{array}$ & & & $3.5 \%$ & & & & $.04 \%$ & \\
\hline
\end{tabular}

${ }^{\mathrm{a}}$ Ref categories (Marital status $=$ Ever Married, Previous Infection Experience $=$ Once infected) ${ }^{*} \mathrm{p}<. \mathrm{I},{ }^{* *} \mathrm{p}<.05,{ }^{* * *} \mathrm{p}<.01$ 
Table 5 shows the parameters of the initial model containing all the seven relevant variables for the two groups. In the non-circulators model, the seven variables in combination reduced the value of the unexplained variation (2logliklehood) in the intercept-only model by $53.5 \%$ in contrast to $41.04 \%$ improvement achieved by the same set of variables in the circulators model. Likewise, the magnitude of explanation (Nagelkerke's $\mathrm{R}^{2}$ ) accounted for by the seven variables in the non-circulators model $(69.3 \%)$ was about $12 \%$ percentage points higher than that in the circulators analysis. Nevertheless, the values of the Hosmer-Lemeshow parameters in the two models, that is, $\chi^{2}=5.443 ; \mathrm{df}=8$ and sig. $=709$ for non-circulators and $\chi^{2}=5.713 ; \mathrm{df}=8$ and sig. $=.679$ for circulators are indicators of good-fit.

Four variables in the non-circulators model namely, marital status, previous experience of sexual infection, business experience and age at first sex exhibit varying levels of statistical significance, compared to only two variables - marital status and previous sexual infection experience - in the circulators model. For each variable, excluding marital status and previous experience of sexual infection, the pattern of likelihood of sexuality risk between the reference and the other comparative categories, exhibit notable contrasts for the two groups.

Both groups show much similarity in the way marital status and the previous experience of sexual infections variables associate with risky sex. Marital status shows that the ever-married categories in both groups exhibit greater likelihood for commercial sex as shown by the Odds ratios of .007 and .028 respectively for the never-married categories of non-circulators and circulators. Likewise, analysis of previous experience of sexual infection shows that those who had never had a previous experience of sexual infection had the greater likelihood for contracting commercial sex, than those who had had a previous experience. The likelihood's results for business experience show a contrasting pattern between the two groups. First, while it is significant in the non-circulators' model, it is not so in the circulators' model. Second, the reference category of the noncirculators, that is, the least-experience group, shows a lesser likelihood for sexuality risk, in contrast to a greater likelihood shown by the same group among the circulators. Age at first sexual experience presents a mixed pattern among the non-circulators subgroups. That is, the earliest-entrant group, which is the reference category, shows a greater likelihood of risky sex than the median entrants; but exhibits a lesser likelihood than the latest entrant group. Among the circulators, however, the earliest entrant group shows a greater likelihood for risky sex than the other two categories.

The final results of the BSTEP $L$ iteration, which produced a parsimonious model for both groups, are depicted in Table 6. Four variables, namely Marital status, previous experience of sexual infection, age at first sex and business experience are retained in the non-circulators model, in contrast to two variables, that is, marital status and previous experience of sexual infection that are retained in the circulators model. The drop of three varia- 
bles in the non-circulators model reduced its $\mathrm{R}^{2}$ by a mere $2.2 \%$. The improvement in the value of the scaled deviance $\left(d_{o}\right)$ dropped minimally by
$5.45 \%$ when compared to the improvement achieved by the model, which had all the variables.

Table 6: Comparative results of the parameters for the final step iteration non-circulators \& circulators

\begin{tabular}{|c|c|c|c|c|c|c|c|c|}
\hline \multirow{2}{*}{$\begin{array}{c}\text { Model Categorical } \\
\text { Variables }\end{array}$} & \multicolumn{4}{|c|}{ Non-Circulators } & \multicolumn{4}{|c|}{ Circulators } \\
\hline & B & SE & Wald & Odds & B & SE & Wald & Odds \\
\hline aMarital status $(\mathrm{I})$ & -4.091 & .553 & $54.816 * * * *$ & .017 & 3.624 & .356 & $\begin{array}{l}103.358 * * \\
*\end{array}$ & .027 \\
\hline $\begin{array}{l}\text { aPrevious experience of } \\
\text { sexual infection(I) }\end{array}$ & 2.282 & .531 & I8.443**** & 9.801 & 1.027 & .353 & 8.457 米米 & 2.794 \\
\hline $\begin{array}{l}\text { Business experience in } \\
\text { years } \\
\text { Minimum Experience } \\
\text { (ref) }\end{array}$ & & & $4.92 I^{*}$ & & \multicolumn{4}{|c|}{ Not retained in Final model } \\
\hline Median Experience (I) & 1.128 & .570 & $3.921 * *$ & 3.090 & & & & \\
\hline $\begin{array}{l}\text { Maximum experience in } \\
\text { years }(2)\end{array}$ & 1.000 & .525 & $3.626 *$ & 2.717 & & & & \\
\hline $\begin{array}{l}\text { Age at first sex } \\
\text { Early entrants (refo }\end{array}$ & & & $9.352^{* * * *}$ & & \multicolumn{4}{|c|}{ Not retained in Final model } \\
\hline Later entrant $(\mathrm{I})$ & .088 & .510 & .030 & 1.092 & & & & \\
\hline Latest entrant (2) & 1.478 & .504 & $8.602 * * * *$ & 4.383 & & & & \\
\hline Constant & -.060 & .522 & .013 & .942 & 1.179 & .256 & 21.192 & 3.250 \\
\hline Nagelkerkes' $\mathrm{R}^{2}$ & \multicolumn{4}{|c|}{$67.1 \%$} & \multicolumn{4}{|c|}{$54.1 \%$} \\
\hline $\begin{array}{l}\text { Hosmer-Lemeshow } \\
\text { Test } \chi^{2,}, \mathrm{df}, \rho\end{array}$ & \multicolumn{4}{|c|}{ 7.258;8;.509 } & \multicolumn{4}{|c|}{$2.172 ; 2 ; .338$} \\
\hline $\begin{array}{l}\text {-2Loglikelihood } \\
\text { improvement }\end{array}$ & \multicolumn{4}{|c|}{$51 \%$} & \multicolumn{4}{|c|}{$37.9 \%$} \\
\hline
\end{tabular}

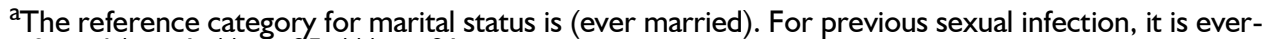
infected ${ }^{*} \mathrm{p}<.1$, ** $\mathrm{p}<.05$; *** $\mathrm{p}<.01$

The Hosmer-Lemeshow parameters of the model indicate that the four variables can be relied upon in modelling the event of commercial sexuality risk for the group. The circulators' model, which retained only two variables, experienced a reduction of $3.3 \%$ in its $R^{2}$ value, as well as a $5.25 \%$ decline in the model improvement value achieved by the full-variable model.

The Hosmer-Lemeshow parameters $\left(\chi^{2}=2.172 ; \mathrm{df},=2 ; \quad\right.$ sig $\left.=.338\right)$ also indicate that the two variables are key model predictors of risky sex for non-circulatory traders. The pattern of the likelihood of risky sex either between or among the different subcategories of the retained variables did not deviate significantly from the pattern observed in their respective allinclusive models. In other words, the once married as well as the never infected groups were more vulnerable groups than their respective reference 
categories, for both non-circulators and circulators.

Among the non-circulators, however, a minor change occurred in the final model's outcome on age at first sexual intercourse. The 'later entrant' category, in contrast to what obtained in the all-inclusive model, exhibited a greater likelihood for risky sex than the early entrants group, that is, the reference category. The variable, business experience shows that the minimum experience category exhibits greater likelihood for sexual behavioural risk than the median and the maximum experience groups.

\section{Discussion}

The paper adopted a novel methodology, which enabled it to capture two related population groups, comprising a relatively mobile and a non-mobile group. It confirms the expected biosocial differences be-tween the two groups. In the present study, however, the mobile group is significantly older and consists more of married folks than the non-circulators. Comparative vulnerability to sexuality risks shows that the nature and the context of risk are major parameters to consider. For example, while the records of the age at first sex tend to implicate the noncirculators, the normal mean value of the total sexual partners ever-had, on the other hand, implicated the circulators. A standardization of the total lifetime sexual partners, expressed as an average of sexual partners, since the year of sexual debut, caused a reduction in the value of the circulators' lifetime sexual partners, to a value only marginally above that of the non-circulators. A tentative impression, which requires further analysis, is that the lower value of the mean age at first sexual intercourse for non-circulators may reflect the influence of the generational gap between the older circulators and their younger non-circulatory group. The hazy contrast indicated by lifetime sexuality risk parameters differs from the sharp contrast exhibited by the lastone year parameters on multi-partner sex and commercial sex patronage. While the circulators were more vulnerable on multi-partner sex, the noncirculators show greater risk tendency on commercial sexual partnership; although in the latter case the result is marginally insignificant. The outcome of condom-use analysis was also statistically undifferentiating be-tween circulators and non-circulatory traders.

The results of the logistic models show that despite the notable biosocial differences between the two groups, the major factors, which account for observed variations in the occurrence of commercial sex patronage in the two populations are quite identical. Marital status and the previous experience of sexual infections accounted for more than $50 \%$ of observed variations in whether one engages or not in commercial sex, irrespective of circulatory status. The two other variables in the non-circulators' final model at a closer look, accounted for less than $17 \%$ of the $67 \%$ 'explanation' yielded by the final model containing four variables. Furthermore, for both population groups, the orientation of contrast between the reference and other category(ies) are to a large extent similar. For example, the ever-married groups in both cases exhibit the greater likelihood for risky sex respectively in the 
two final iterated models.

\section{Conclusion}

The quantum of research on sexual behaviour in Nigeria appears quite substantial. The fact however, is that the state of knowledge, as to whether and how its mobile population groups differ from their relatively 'immobile' counterparts on HIV/AIDS risk-prone sexual practices, is yet to be thoroughly examined. Besides, the assumption that mobile groups constitute greater sexuality risks than their non-mobile counterparts has hardly been thoroughly examined to determine its veracity and the ramification of the claim. Two major reasons have no doubt contributed to the observed gap in research. First, the inherent logistical challenge of contriving a valid sampling frame that could provide a basis for scientific analysis of data obtained from such exercise is enormous. The second is the conservative perception of sexual behaviour information as confidential matters. The advent of HIV/AIDS on the one hand, and the attendant research and the intervention programmes that emanated from them, appear to be contracting the frontiers of conservatism, although at a rather slow pace.

To facilitate the acquisition of relevant information on the various issues of human development, including the sexual health of mobile population groups, it is advised that governments at various levels should set up agencies that will fraternize with the affected groups. Such agencies would liase also between the groups and research institutions and agencies.

The observed nature of association between marital status and risky sexual partnership necessitates that both governments and other cooperating agencies should sponsor more programmes which promote marital fidelity and love. Results show that the ever-married folks in both groups have greater likelihood for risky sex. This suggests that marital love is diminishing, thereby increasing the degree of paid-for sex by those currently in marital unions, and amplifying the chances of sexual infections.

On the other hand, the finding that a previous experience of a sexually transmitted infection (EVHADSTI), is statistically significant for both groups is a good indication. By inference it shows the reasonableness of the move by various organizations to employ the services of HIV/AIDS victims in spreading the campaign against the imbibitions of risky sexual behaviour. Their capability to express both pains and other personal experiences convincingly may influence the laggards to shun risky sexual practices. This may be complemented with recorded real life programmes that depict the trauma of being an HIV/AIDS sufferer.

Finally, previous efforts by both governments and related agencies to address reproductive health problem of HIV/AIDS have explored the markets as a major domain for intervention programmes. A major question that is posed to the application of this strategy is whether researchers generally anticipate subtle within- and between-groups differences that may exist in the different markets and their implications for research design, as well as on the specific content of intervention. This study has shown that the affinities for observed risky sexual practices are not 
identical between traders who circulate and those who do not. Given that differences in the nature, as well as the degree of imbibed risk may affect the spread of infection in a population, it is pertinent to further explore whether the present findings generally apply to other recognizable societal groups, which are reasonably segmented in terms of the spatial mobility dimensions of their livelihoods and their healthrelated implications.

\section{References}

Adegbola, O. and Babatola O. 1999. "Premarital and Extramarital Sex in Lagos, Nigeria". The Continuing HIV/AIDS Epidemic in Africa. HTC, ANU., Canberra 19-44

Anarfi, J. .. 1993. "Sexuality, Migration and AIDS in Ghana - a Socio-behavioural Study". Health Transition Review 3 (Supplement). 45-68.

Anarfi, J. $\square$, Ernest W. Appiah and $\square$ ofi Awusabo-Asare 1997."Livelihood and the Risk of HIV/AIDS Infection in Ghana: The Case of Female Itinerant Traders". Health Transition Review, Supplement to Vol. 7.

Anarfi, J. . . 1992. "Sexual Networking in Selected Communities in Ghana and the Sexual Behaviour of Ghanaian Female Migrants in Abidja, Cote d'Ivoire." pp. 49-64 in Sexual Behaviour And studies on the transmission of HIV, ed T. Dyson. Liege: Derouaux-ordina.

Anarfi, J. . . and Antwi P. 1995. "Street Youth in Accra city: Sexual Networking in a High-Risk Environment and its Implications for the Spread of HIV/AIDS." Health Transition Review, Supplement to Vol. 5, |3|-|5|.

Babatola, O. 2006. International Popu- lation Mobility and the Risk to Sexual health in Lagos, Nigeria. An Unpublished Ph.D. Thesis submitted to the Department of Geography, University of Lagos, Nigeria.

Caldwell J. C., Orubuloye I. O. and Caldwell. P. 1994. "Methological Advances in Studying the Social Context of AIDS in West Africa". pp. $\mathrm{I}-12$ in I.O. Orubuloye, J. C. Caldwell, Pat Caldwell and Gigi Santow (eds) Sexual Networking and AIDS in Sub-Sahara Africa: Behavioural Research and the Social Context Canberra: Australian National University

Ekanem, E.E.; Afolabi, B.M., Nuga, A.O. and Adebayo, S.B. 2005. "Sexual behaviour, HIV-related Dnowledge and Condom Use by intra-city commercial bus Drivers and Motorpark Attendants in Lagos Nigeria". African Journal of Reproductive Health, 9(I):

Hopkins, W. G. 200I. "A New View of Statistics Internet Society for Sport Science":

http/ww w.sports.org/resources/stats/. Accessed 15/6/2006.

Lurie, M N. William B.G., Zuma, 7 ., Mkaya-Mwamburi D. , Garnett G.P, Sturm A.W. et al. 2003. "The Impact of Migration on HIV-I Transmission in South Africa: A study of Migrant and non-migrant men and their partners." Sexually Transmitted Diseases, 30 (2): 149-156.

Marck, J. 1999. 'Long-distance truck drivers' sexual cultures and attempts to reduce HIV risk behaviour amongst them: A review of the African and Asian literature". Resistance to behavioural Change to Reduce HIV/AIDS Infection. 91-100 Mudandi, C., Vissers, D., Habbema, D., 
Gregson, S. 2006. "No difference in HIV incidence and sexual behaviour between out-migrants and residents in rural Manicaland, Zimbabwe" Tropical Medicine and international Health, II(5): 705711.

NACA 2005 HIV/AIDS: National Strategic Framework for Action (2005 2009) Published by The Society for Family Health.

Omorodion F.I. 1993 "Sexual Networking among Market Women in Benin City, Bendel State" Health Transition Review 3 Supplemetary Issue pp. III.

Orubuloye, I.O., P. Caldwell and J.C. Caldwell. 1993. "The role of highrisk occupations in the spread of AIDS: truck drivers and itinerant market women in Nigeria". International Family Planning Perspectives 19:43-48,7I.

Orubuloye, I. O., J. C. Caldwell and P. Caldwell. 1994. "Diffusion and focus in sexual networking: identifying partners and partners' partners". pp. 33-43 in Sexual Networking and AIDS in Sub-Saharan African: Behav- ioural Research and the Social Context, (eds). I. O. Orubuloye, J. C. Caldwell, Pat Caldwell and Gigi Santow. Canberra: Australian National University.

Orubuloye, I. O. and Folakemi Oguntimehin. 1999. "Death is preordained, it will come when it is due: attitudes of men to death in the presence of AIDS in Nigeria". Resistances to Behavioural Change to Reduce HIV/AIDS Infection. 10IIII.

Osagbemi M.O.; Adepetu, A.A.; Nyong, A.O. and Jegede, A.S. 2007. "Spouse-sharing and experience with sexually transmitted Diseases among the Okuns of Nigeria". (UAPS) Union for African Population studies 22:2 Dec. p. 107-126

Prothero, R.M. 1977. Disease and human mobility: a neglected factor in epidemiology. International Journal of Epidemiology 6:259-267.

Varga, A. 1997. "Barriers to condom use among commercial sex workers in Durban, South Africa." African Journal of Reproductive Health, I(I): 74-8 